\title{
Cartas do hospício: Memória e esquecimento - rastros e insurgências
}

\section{Hospice letters: Memory and forgetfulness - traces and insurgency}

\section{Cartas desde el hospicio: Memoria y olvido - rastros y insurgencia}

\section{Tiago Marcelo Trevizani*}

Universidade Federal do Rio Grande do Sul - UFRGS, Porto Alegre, Rio Grande do Sul, Brasil

\section{Rosane Azevedo Neves da Silva**}

Universidade Federal do Rio Grande do Sul - UFRGS, Porto Alegre, Rio Grande do Sul, Brasil

\begin{abstract}
RESUMO
Este artigo discute sobre o uso de cartas como fontes de pesquisa e sua articulação com os conceitos de memória e esquecimento, no âmbito da história da loucura. Os autores partem do encontro ao acaso com algumas correspondências escritas no início do século XX, por pacientes do antigo Hospício São Pedro, localizado em Porto Alegre (Rio Grande do Sul/Brasil), as quais ficaram guardadas nos seus prontuários e que, aparentemente, não foram enviadas aos seus destinatários. Os procedimentos de exclusão e a regulação dos discursos daqueles que eram tidos como loucos operou um silenciamento desses sujeitos, tomando seus escritos, exclusivamente, como referentes da sua suposta loucura; entende-se que a dinâmica das relações de poder é capaz de produzir "vidas memoráveis" e "vidas pouco dignas de serem lembradas". Destaca-se o compromisso ético-político de uma perspectiva histórica que se compromete com a "memória dos oprimidos". Este estudo examina alguns "rastros do passado", entendendo-os como possibilidade de insurgência daqueles que foram relegados ao esquecimento, neste caso, lembrar do passado é intervir no presente.
\end{abstract}

Palavras-chave: cartas do hospício, loucura, memória e esquecimento.

\section{ABSTRACT}

This article discusses the use of letters as source of research and their articulation with the concepts of memory and forgetfulness, within the history madness. The authors start from the encounter by chance with some correspondences written, in the beginning of the 20th century, by patients of the former Hospício São Pedro, located in Porto Alegre (Rio Grande do Sul/Brasil), which were kept in their medical records and, possibly, were not sent to their recipients. The procedures of exclusion and the regulation of the discourses of those who were considered crazy operated a silencing of these subjects, taking their writings exclusively as referents of their 
supposed madness; it is understood that the dynamics of power relations is capable of producing "memorable lives" and "lives not worthy of being remembered". The ethical-political commitment of a historical perspective engaged with the "memory of the oppressed" is highlighted. This study examines some "traces of the past", understanding them as the possibility of insurgency of those who have been relegated to oblivion; in this case, remembering the past is intervening in the present.

Keywords: hospice letters, madness, memory and forgetfulness.

\section{RESUMEN}

Este artículo discute sobre el uso de cartas como fuentes de investigación y su articulación con los conceptos de memoria y olvido dentro de la historia de la locura. Los autores parten desde el encuentro por casualidad con algunas correspondencias escritas, a principios del siglo $\mathrm{XX}$, por pacientes del antiguo Hospício São Pedro, ubicado en Porto Alegre (Rio Grande do Sul/Brasil), las cuales quedaron guardadas en sus expedientes clínicos y que, posiblemente, no fueron enviadas a los suyos destinatarios. Los procedimientos de exclusión y la regulación delos discursos de aquellos que eran tenidos como locos opero un silenciamiento de esos sujetos, tomando sus escritos, exclusivamente, como referentes de su supuesta locura; se entiende que la dinámica de las relaciones de poder es capaz de producir "vidas memorables" y "vidas poco dignas de ser recordadas". Se destaca el compromiso ético-político desde una perspectiva histórica que se compromete con la "memoria de los oprimidos". Este estudio examina algunos rastros del pasado, entendiéndolos como posibilidad de insurgencia de aquellos que fueron relegados al olvido; en este caso, recordar el pasado es intervenir en el presente.

Palabras clave: cartas desde el hospicio, locura, memoria y olvido.

Este artigo discute sobre o uso de cartas como fontes de pesquisa e sua articulação com os conceitos de memória e esquecimento. A análise parte do encontro com algumas correspondências escritas, no início do século XX, por pacientes do antigo Hospício São Pedro, localizado em Porto Alegre (Rio Grande do Sul/Brasil).

O encontro com esse conjunto de documentos, que estamos denominando como "cartas do hospício", aconteceu ao acaso, quando desenvolvíamos uma outra pesquisa que analisava prontuários de pacientes que foram internados no Hospital Psiquiátrico São Pedro a1 na passagem do século XIX para 0 século $X X$. Enquanto examinávamos as caixas empoeiradas que armazenam esses documentos clínicos a2, localizamos dezessete cartas escritas entre os anos de 1909 e 1912 por dois pacientes, Pierina e Isauro a3, as quais ficaram arquivadas dentro de suas respectivas papeletas médicas.

Nessas cartas, os internos desse asilo de alienados escrevem aos seus familiares, amigos e outras pessoas de suas relações. Contam sobre suas vidas, suas desventuras e seu cotidiano. Pedem notícias da tia que ficou doente de cama; pedem rosários para as suas preces; pedem travesseiros e cobertas por causa do frio; e, não 
poucas vezes, suplicam que Ihes tirem do hospício. Essas missivas, no entanto, não foram enviadas aos seus destinatários, considerando que se mantiveram anexadas aos prontuários dos seus remetentes. As únicas correspondências que talvez tenham sido lidas pelos destinatários foram aquelas endereçadas aos médicos assistentes do hospício. Vale dizer que tanto Pierina, quanto Isauro remeteram cartas aos alienistas do São Pedro.

Os estudos no campo da Saúde Mental no Brasil mostram que uma parcela significativa de pesquisas nessa área estabelece articulações com a História, dialogando com suas concepções epistemológicas e lançando mão de suas ferramentas metodológicas. Circunscreve-se, portanto, um campo temático que se desdobra em "história da psiquiatria e do alienismo", "história da loucura", "história das doenças mentais". Os levantamentos bibliográficos realizados por Venancio e Cassilia (2010), Lima e Holanda (2010) e Wadi (2014) apresentam o crescente número de produções científicas nessa área nos últimos anos, assim como os diferentes paradigmas historiográficos que os sustentam. Esses autores mostram que, apesar de haver um aumento de estudos abordando tal temática, ainda há lacunas temporais e geográficas, considerando que certos períodos históricos e certas regiões do Brasil contam com poucas pesquisas que discutem esse assunto. De acordo com esses levantamentos bibliográficos, as produções científicas sobre a história da psiquiatria e da loucura concentram-se principalmente nas regiões sudeste e sul do Brasil.

As fontes consultadas nos estudos sobre a história da psiquiatria e da loucura, conforme Venancio e Cassilia (2010), Lima e Holanda (2010) e Wadi (2014), são bastante diversificadas. As pesquisas nessa área analisam leis, ofícios, atas, relatórios administrativos, periódicos científicos, textos literários, documentos clínicos e outros.

Muitos trabalhos provenientes da região sudeste giram em torno do Hospício de Pedro II (ou Hospício Nacional de Alienados) que foi o primeiro estabelecimento do Brasil destinado àqueles que sofriam de alienação mental. Fundado em 1852, no Rio de Janeiro (que na época era a capital Federal), esse hospício foi um cenário importante para a história da loucura e da psiquiatria dos séculos XIX e XX.

Considerando que pretendemos discutir sobre o uso das fontes nas pesquisas, destacamos o relato de Facchinetti, Ribeiro, Chagas e Reis (2010); as autoras mencionam a importância de terem acessado os prontuários dos pacientes do Hospício Nacional de Alienados para o estudo que desenvolviam sobre as influências do alienismo francês e alemão nas práticas psiquiátricas na capital do Brasil, no início do século XX. As pesquisadoras, inicialmente, estavam trabalhando com artigos publicados por alienistas e médicos em um periódico específico, os Arquivos Brasileiros de Psiquiatria, Neurologia e Ciências Afins. Elas afirmam que o acesso a esses documentos 
clínicos permitiu estabelecer relações e comparações com os textos científicos da época e possibilitou conhecer um pouco do cotidiano do hospício, assim como os percursos e destinos dos moradores. Além disso, nesse mesmo texto, apresentam o trabalho de sistematização de um conjunto de fontes referentes ao Hospício Nacional que foram reunidas e publicadas na Biblioteca Virtual em Saúde para América Latina e Caribe, o que constitui uma importante base de dados para pesquisas na área.

No Rio Grande do Sul, muitos trabalhos sobre a história da psiquiatria e da loucura estão relacionados com o Hospício São Pedro. Salientamos a relevância da pesquisa de Wadi (2002) que examina vários relatórios administrativos e documentos legais que narram a história da luta pela construção de um asilo para alienados na Província de São Pedro a4, assim como os discursos e as práticas do alienismo e da psiquiatria, entre os anos1860 e 1930, tendo como cenários a Santa Casa de Misericórdia de Porto Alegre e o Hospício São Pedro. Podemos citar também os estudos de Scotti (2011; 2013) que discutem a questão da loucura e sua relação com a história da imigração alemã e italiana em terras gaúchas, partindo da análise de prontuários do Hospital Psiquiátrico São Pedro. Os discursos sobre as patologias de crianças e adolescentes são problematizados nas pesquisas de Silva, Hartmann, Scisleski e Pires (2008) e Trevizani e Silva (2014); os autores analisam os motivos de internação e os diagnósticos atribuídos a pacientes que foram internados no Hospício São Pedro antes dos dezoito anos de idade, entre os anos 1884 e 1937; para isso, também tomam como fontes de pesquisa os prontuários desse estabelecimento, alguns relatórios administrativos dos provedores da Santa Casa de Misericórdia e dos médicosdiretores do hospício, além de artigos publicados em periódicos científicos, como os Archivos Brasileiros de Hygiene Mental.

Elencamos, por fim, as produções de Wadi (2003) e Santos (2008) que analisam escritos epistolares como fontes de pesquisa no contexto da história da loucura. Os estudos dessas autoras (que serão melhor apresentados na sequência) são extremamente importantes para a discussão que empreendemos aqui, considerando a semelhança (e até mesmo a coincidência, no caso das cartas de Pierina) dos objetos empíricos delas com os nossos.

Feito esse breve levantamento de alguns trabalhos que abordam a temática da história da psiquiatria e da loucura e um mapeamento de suas respectivas fontes de pesquisa, podemos então prosseguir com a reflexão que nos propomos neste texto. Pretendemos discutir sobre o uso das cartas como fontes primárias e sua singularidade no que tange a esse campo do conhecimento, estabelecendo algumas articulações com os conceitos de memória e esquecimento. 


\section{Cartas}

"Como o amigo tem dado-me innumeras provas de attenções sinseras quero que leves em consideração o que escrevo com o coração cheio de magoa" a5. Com essa recomendação a respeito das linhas recém escritas, Isauro principiava seus sinceros cumprimentos de despedida nessa epístola que escrevera durante sua internação no Hospício São Pedro. Redigida com caligrafia caprichada, repleta de cortesias e prodigioso vocabulário, essa carta foi endereçada ao amigo Hipólito, no início de junho de 1912.

Arrastavam-se os dias tenebrosos de recolhimento naquele "asilo de alienados", quando o jovem telegrafista escreveu esse desabafo, em tom um tanto melancólico, mas não de todo desesperançoso, a esse amigo, de quem pouco se sabe. Aliás, sabe-se muito pouco também sobre Isauro. O que dele conhecemos são parcimoniosos fragmentos de sua história, registrados no seu prontuário e nas cartas que produziu enquanto esteve internado.

Isauro poderia muito bem ser contado entre aqueles que Foucault (2006a) chamou de "homens infames". Entre aqueles que engrossam uma antologia de existências, cujas histórias de vida não guardam em si nada de heroico ou glorioso que merecesse qualquer registro nas crônicas da humanidade; pelo contrário, Isauro está entre as existências que são tidas como insignificantes e desprezíveis; entre uma multidão de anônimos, destinados a passar sem deixar rastros, vidas condenadas ao esquecimento.

Talvez o aspecto que mais nos cause perplexidade em relação ao encontro com esses documentos é o fato de eles estarem guardados dentro dos prontuários dos pacientes, o que nos leva a pensar que, possivelmente, essas cartas não foram enviadas aos seus destinatários, pelo menos a maioria delas, permanecendo esquecidas no arquivo e relegadas ao silêncio.

Aqueles que se dedicam ao trabalho com fontes primárias de pesquisa sabem que há uma multidão de histórias que se aglomeram nas caixas e prateleiras dos arquivos históricos. Algumas dessas histórias passam a ter visibilidade pelo encontro dos pesquisadores com os documentos, como afirma Lobo:

O que as faz às vezes ressurgir [as histórias] é o acaso do encontro de documentos esparsos com a intenção de quem as perscruta. Nada têm de grandioso [essas vidas], mas guardam certa grandeza no sofrimento, revelam muito do seu tempo em seu fugidio clarão, e certamente, foram objeto de ódio, piedade ou desprezo de seus contemporâneos. Foram vidas detidas por uma instituição, aprisionadas pelas condições que lhes foram impostas, maldições das relações de poder, e das quais restam apenas alguns vestígios, poucas frases, atas apressadas e 
documentos burocráticos, prontuários médicos, pequenos relatos, fotos e imagens desbotadas de sua má sorte. Esse acontecimento tão pouco provável que as faz reaparecer em sua insignificância pôde dar-se não só pela paciência de quem as leu com intensidade, mas principalmente porque conseguiram sobreviver ao descuido a que está relegada a maior parte dos arquivos brasileiros (Lobo, 2008, p. 18).

No caso das cartas do hospício, foi, certamente, o encontro fortuito dos pesquisadores com esse conjunto de documentos que pode fazêlos aceder à condição de uma lembrança; foi o demorar-se na leitura daquilo que surgiu ao acaso; foi a espreita "lá onde menos se os esperava" que pôde dar a eles alguma visibilidade (Foucault, 1979, p. 15).Nossas incursões pelo arquivo, neste caso, possibilitaram "o aparecimento tenso de um acontecimento inesperado...o foco [foi direcionado] sobre alguns instantes da vida de personagens ordinários, raramente visitados pela história" a6 (Farge, 1989, p. 13, tradução nossa).

A respeito das cartas, transformadas em objetos de pesquisa, podese dizer que a epistolografia tem despertado interesse em estudiosos de diversas áreas do conhecimento por ser um gênero textual bastante plural que abarca elementos biográficos dos seus autores e destinatários e retrata algo da época em que os textos foram escritos. O corriqueiro uso que fazemos do e-mail em nossos tempos parece ter decretado a obsolescência das cartas; apesar disso, essa tecnologia de comunicação, ainda que considerada ultrapassada, guarda em si um certo fascínio. Nas palavras de Galvão (2008, p. 15): "A disseminação do computador acabou com a carta e, na hora em que a matou, descobriram que era um objeto precioso".

Costuma-se dizer que uma carta aproxima os ausentes. Tais documentos funcionam num "entre distâncias" (seja para diminuí-las, seja para aumentá-las). Ela constitui-se em um campo híbrido à medida que produz certa sociabilidade, ao mesmo tempo em que flerta com a intimidade, estabelecendo um território entre o público e o privado, colocando para funcionaras tramas da produção das subjetividades. Segundo Foucault, a correspondência:

... constitui também uma certa maneira de se manifestar para si mesmo e para os outros. A carta torna o escritor 'presente' para aquele a quem ele envia. É presente não simplesmente pelas informações que lhe dá sobre a sua vida, suas atividades, seus sucessos e fracassos, suas venturas e desventuras; presente com espécie de presença imediata e quase física (Foucault, 2004, p. 155). 
Uma carta instaura uma temporalidade e uma espacialidade, produzindo ressonâncias, encontros e partilhas, compondo uma história e uma geografia sempre inéditas. Uma correspondência agencia uma reunião de narrativas, não somente dos dramas a que se refere e dos enredos que registra, omite e fabula, mas também dos carimbos que recebeu, dos mecanismos de entrega e de extravio a que foi submetida, das paisagens por onde passou. Acumulam-se aos movimentos de partida e chegada o peso das digitais daqueles que a manusearam; os frisos milimetricamente dobrados e os vincos amassados acidentalmente; as rasuras, os borrões e os tremores de um titubeio da mão que a escreveu ou da língua que gaguejou; somam-se à superfície da carta as luzes e as sombras que ela habitou.

\section{Do Hospício}

Illmo. Snr. Dr. Dioclecio Pereira

e mais membros da directoria H. São Pedro

Saudações affectuosoas

Eu abaixo assignado natural d'este estado com vinte annos de idade, venho respeitosamente informar-me de V.asS. as porque motivo fui internado n'este Hospício, pois como vossas idoneas pessoas não devem ignorar, eu não estive e nem estou doido e nem tão pouco doente, e se por infeliz sorte estivesse, ainda tenho a casa paterna.

Espero deferimento

Isauro

Porto Alegre 9 de junho de 1912 a7

A cena épica da libertação dos grilhões que prendiam os loucos no Hospital de Bicêtre em Paris, supostamente protagonizada pelo médico francês Philippe Pinel, é considerada por muitos como o nascimento da Psiquiatria Moderna. Segundo Foucault (2006b; 2007), no início do século XIX, a loucura fora "encampada" pelos saberes médicos e suas prerrogativas humanistas e filantrópicas, passando a ser entendida socialmente como "doença mental". O surgimento do alienismo, como ficou conhecida inicialmente a psiquiatria, fazia surgir um especialista, a saber, o alienista, e circunscrevia um determinado local para os doentes: o hospício.

O hospício tornaria possível a prescrição do "tratamento moral" apresentado por Pinel no seu "Traité Médico-Philosophique sur L'Aliénation Mentale ou La Manie", publicado em 1801. Essa terapêutica tinha como princípio $o$ isolamento dos alienados em 
asilos, onde a própria organização espacial teria uma função primordial no desenvolvimento da cura. De acordo com as concepções da época, a internação permitia o afastamento dos loucos do contexto desencadeante da loucura e possibilitava o acompanhamento intensivo dos pacientes pela figura do alienista, o qual exercia um papel fundamental no que se referia à ortopedia moral daqueles que estavam acometidos dos "desvios da razão".

As narrativas da história da psiquiatria no Brasil, publicadas nos trabalhos de Machado, Lureiro, Luz e Muricy (1978), Costa (1989), Engel (2001) e de outros autores, mostram o quanto o pensamento do alienismo francês esteve presente nos discursos e nas práticas da psiquiatria brasileira nos séculos XIX e XX. No Hospício São Pedro, assim como em outros estabelecimentos congêneres que foram criados no país naquele período, é perceptível essa influência, haja vista a ênfase dada ao pressuposto do isolamento dos alienados como forma de tratamento e correção da loucura.

Referindo-se à fundação de um hospício na Província de São Pedro, Wadi (2002) afirma que, durante o século XIX, surgiram inúmeras manifestações que reivindicavam junto ao governo a construção de um estabelecimento que recebesse os alienados que andavam vagando pelas ruas e praças da capital e do interior, aos quais restava apenas o recolhimento na Santa Casa de Misericórdia de Porto Alegre ou na Casa de Correção da cidade. As condições dessas internações eram degradantes pela superlotação e insalubridade que as acomodações de ambos os locais ofereciam.

Os pedidos pela construção de um hospício eram encabeçados principalmente por cidadãos proeminentes, reconhecidos na política e na filantropia provinciana, que alegavam que tanto o estabelecimento benemérito quanto 0 carcerário não eram propícios para 0 recebimento dessa população, pelos custos que dispendiam (por serem na maioria das vezes pensionistas vitalícios) e pela inespecificidade do atendimento que poderia ser oferecido nessas duas casas (Wadi, 2002).

Depois de anos de insistência, foi inaugurado com festa aquele que viria a se tornar o maior hospício do Rio Grande do Sul. A data escolhida foi 29 de junho de 1884, dia do padroeiro da Província de São Pedro, que emprestou o nome também à casa de tratamento dos insanos. Situado a algumas léguas do centro de Porto Alegre, na Estrada do Mato Grosso (hoje Avenida Bento Gonçalves), o prédio em estilo neoclássico, depois de completamente pronto, tornou-se um cartão postal da cidade pela sua imponência arquitetônica e pelo avanço científico que esse tipo de instituição representava para sociedade naquela época.

Com Foucault (2006b; 2007; 2011a) entendemos que o hospício se constitui como um dos mecanismos do poder disciplinar que age no esquadrinhamento dos corpos e das condutas com a intenção de 
torná-los dóceis e úteis. A disciplina estabelece a ordem no asilo e, ao mesmo tempo, dispõe de certos modos de exercício do poder, sendo que sua distribuição tende a se dar de forma assimétrica e não recíproca, produzindo, em alguns casos, aquilo que Foucault (2006c) chamou de "estados de dominação", quando as relações de poder, ao invés de serem móveis e dinâmicas, encontram-se cristalizadas e fixas, impedindo a reversibilidade do movimento, restringindo e limitando as práticas de liberdade.

Reclusos entre os muros e arames farpados de uma instituição total e capturados em uma trama discursiva redundante que insiste em reduzi-los exclusivamente aos significantes da "loucura", os loucos são incluídos no ordenamento social por meio de sua exclusão. Os procedimentos de segregação ocorrem por serem considerados "potencialmente perigosos" (perigosos à ordem social, perigosos à raça humana pela transmissão hereditária de suas degenerações).

Os princípios do isolamento, da organização do espaço terapêutico, da vigilância e distribuição do tempo regem a totalidade da vida dos alienados, atingem cada minuto da sua existência. Ao mesmo tempo que inscrevem individualmente o alienado, percorrendo a minúcia de seus corpos, de seus gestos (Machado et al., 1978, p. 443).

No hospício, portanto, mesmo as ações mais corriqueiras, mesmo aquelas costumeiramente entendidas como de "foro íntimo", como é - caso da comunicação epistolar, passam a ser alvo de um esquadrinhamento por parte dos mecanismos disciplinares que se ocupam dos ínfimos movimentos da vida dos internos. Tornam-se evidentes as características de uma instituição total, que esboça um conjunto de estratégias de segregação, coerção, burocratização e disciplinamento da subjetividade.

O encontro com as cartas do hospício suscita a surpresa de localizar aquilo que não esperávamos, onde não esperávamos. Como alguém que anda distraído na beira da praia e sem querer se depara com uma mensagem dentro de uma garrafa e se vê assombrado por esse inusitado encontro. Não fomos, entretanto, os únicos que encontramos documentos como esses que causam tamanho espanto. Beveridge publicou, em 1997, um artigo em que analisa 1151 cartas escritas, entre 1873-1908, por pacientes do Royal Edinburgh Asylum, na Escócia. As cartas também foram mantidas nos seus prontuários e relatam situações do cotidiano e descrevem seus sofrimentos. "Os pacientes escreviam por várias razões: para descrever seus tormentos, para dar sentido às suas angústias, para reclamarem ou para defenderem sua sanidade" a8 (Beveridge, 1997, p. 900, tradução nossa). 
Lavín (2003) reuniu e publicou um conjunto de vinte e duas cartas escritas nas primeiras décadas do século XX por pacientes da antiga Casa de Orates, no Chile, as quais também não foram enviadas. Ela as encontrou enquanto procurava alguns documentos em um velho escritório da biblioteca da instituição. Essas cartas "sobreviveram a um incêndio que destruiu grande parte da biblioteca do antigo Instituto Psiquiátrico. Alguém as tomou e guardou amorosamente nessa caixa que encontrei muito tempo depois" a9, diz a autora (Lavín, 2003, p. 7, tradução nossa).

Ríos (2004) localizou cartas e outros escritos pessoais que foram anexados aos prontuários de pacientes do Manicômio General La Castañeda, no México, a partir de 1900. O número de cartas localizadas por ele não foi tão expressivo (se comparado com a quantidade de documentos localizados no asilo escocês), considerando que a maioria dos pacientes mexicanos não eram alfabetizados. Nas palavras do autor: “... pretendo demonstrar a forma como uma minoria de internos letrados articularam em um discurso coerente o desprezo ao conceito psiquiátrico de loucura, às práticas terapêuticas e às relações sociais que regulavam a vida cotidiana do manicômio" a10. (Ríos, 2004, p. 21, tradução nossa).

Villasante, Vázquez dela Torre, Conseglieri e Huertas (2016) escrevem sobre as mais de cem cartas, redigidas entre 1900 e 1950, que foram encontradas nos prontuários do Manicômio Nacional de Santa Isabel en Leganés, na Espanha.

(...) nunca foram transmitidas [as cartas] pelos responsáveis do estabelecimento, que as ajuntaram à história clínica do escrevente como documento anexo capaz de ilustrar ou confirmar a patologia do sujeito, ou como informação adicional que avaliavam suas "resistências" ao internamento. a11 (Villasante et al., 2016, p. 123, tradução nossa).

Wadi (2003) analisou as cartas de Pierina, as quais estavam guardadas em sua papeleta médica que se encontra nos arquivos de documentos clínicos do Hospital Psiquiátrico São Pedro. A autora relaciona a escrita epistolar da jovem agricultora, proveniente do interior do Estado, aos dados do seu prontuário e ao processo criminal, onde era acusada de haver cometido o infanticídio da própria filha.

Santos (2008) estudou as doze cartas e um versinho escritos por T.R., durante os quatro meses de internação no Hospital Psiquiátrico São Pedro no ano de 1937. Esses textos formaram um arquivo involuntário de um escritor que tinha verdadeira paixão pela escrita. A autora, ao refletir sobre as narrativas da loucura, lançou mão de diferentes fontes (diários, cartas, romances) para discutir sobre a escritura daqueles tidos como louco. 
No que se refere às cartas que encontramos nos prontuários do Hospício São Pedro, não se sabe quais foram os motivos para o possível não envio aos destinatários. Vale esclarecer que não nos interessa aqui conjecturar essas razões ou suscitar qualquer tipo de "julgamento moral" daqueles que não o fizeram no devido tempo. Apesar disso, não podemos deixar de perceber que, de modo geral, a escrita dos loucos nos hospícios tende a ser subjugada à insignificância, porque funciona, de acordo com essa perspectiva, como referente das "perturbações mentais" de quem escreve. A palavra do sujeito, nesse caso, é radicalmente desconsiderada, e os escritos daqueles tidos como alienados são tomados, simplesmente, como reiterações de sua loucura, como mostra Engel (2001, p. 156):

Mas as formas de expressão dos indivíduos suspeitos de alienação não seriam analisadas apenas por meio da fala... Assim, cartas pessoais, diários íntimos e, até mesmo, opúsculos, panfletos, livros, publicados ou inéditos, eram vistos pelos médicos-psiquiatras e legistas como verdadeiros mapas da mina, cuja decifração viabilizaria a elaboração de diagnósticos seguros. Tal perspectiva já havia sido claramente expressa pelo Dr. A. F. dos Santos ao recomendar o exame atento de "quaisquer documentos procedentes da pena do alienado".

Cunha (1986) afirma que a correspondência dos internos do Hospício do Juquery era submetida à "censura", sendo que a maior parte acabava sendo incorporada aos prontuários, especialmente se tratasse das condições em que viviam os alienados naquele hospício. As cartas passavam a ser um documento médico que confirmava o suposto estado mórbido e a necessidade de internação desses sujeitos.

O Regulamento do Hospício São Pedro, datado de 1903, citado por Wadi (2011, p. 257), apresenta a seguinte normativa: "Nenhum escripto pode ser recebido ou enviado pelos enfermos sem prévia auctorisação dos médicos" que corrobora com a afirmação dessas autoras.

Tais constatações denotam o quanto esses procedimentos de regulação da vida associam todo o repertório expressivo de um sujeito a um único campo de significação que, neste contexto, é a sua suposta condição de "loucura". Ao mesmo tempo, circunscrevem um determinado modo de funcionamento institucional no qual as estratégias de vigilância e controle dos corpos e das condutas daqueles considerados como loucos ganham dimensões espantosas. 


\section{Memória e Esquecimento}

"Quanto ao doente mental, ele é sem dúvida nenhuma o resíduo de todos os resíduos, o resíduo de todas as disciplinas" (Foucault, 2006 b, p. 67). Considerados como restos, os loucos estão fadados ao esquecimento, como uma operação ativa das relações de poder que são capazes de produzir "vidas memoráveis" e "vidas esquecíveis". Referimo-nos à instauração de um campo de batalha, como aponta Foucault (2011b), no qual alguns discursos são validados e legitimados, ao passo que sobre outros incidem os procedimentos de exclusão, interdição, dominação e silenciamento. Pode-se dizer, portanto, que há uma relação intrínseca entre discurso e poder, que por sua vez coloca para funcionar os mecanismos da memória e do esquecimento.

A pesquisa de Weinrich (2001) tornou-se uma referência importante nas discussões a respeito da memória e do esquecimento. O autor desenvolveu um estudo minucioso sobre a origem etimológica do vocábulo "esquecimento", dedicando a essa temática todo o primeiro capítulo da sua obra "Lethe", na qual o linguista traça aquilo que poderíamos chamar de "uma história cultural do esquecimento", partindo da análise de obras clássicas da literatura europeia. Nesse itinerário etimológico, Weinrich (2011) localiza no grego antigo um conceito que, inicialmente, pode parecer absolutamente estranho, mas que logo assume uma posição um tanto esclarecedora no entendimento da noção de esquecimento que ele propõe. Trata-se da palavra "aletheia" que quer dizer "verdade". Sua formação reúne o prefixo negativo "a", ao radical "leth", que designa algo encoberto, oculto, latente. A verdade, nessa perspectiva, poderia ser entendida como o que não está encoberto, não-oculto, não-latente; a verdade, portanto, como o "não esquecível" ou como aquilo que precisa ser tirado do esquecimento. O esquecimento, que no uso corrente da linguagem é frequentemente utilizado junto com verbos modais na forma negativa ("não poder esquecer", "não querer esquecer", "não cair no esquecimento" ...), assume uma dimensão sombria e trevosa. Isso porque a partícula "leth" (presente na tecla "delete" dos teclados dos computadores) remete ao apagamento e aparece também no nome "Lethe", que na mitologia representa o rio do esquecimento, cujas águas correm no submundo conferindo esquecimento às almas dos mortos, tornando liquefeitas, ou poderíamos dizer, liquidadas, as suas memórias.

Sobre essa associação da morte com o esquecimento, Farge (1989), falando sobre seu trabalho com as fontes primárias na pesquisa histórica, afirma que elas parecem

... realizar um milagre, o de religar o passado ao presente; ao descobrir [os documentos], podemos pensar que não 
trabalhamos mais com os mortos (a história é evidentemente, antes de tudo, um trabalho com a morte), e que seu material é tão agudo que solicita simultaneamente a afetividade e a inteligência. Sentimento raro que esse repentino encontro com essas existências desconhecidas, ásperas e pujantes, as quais entrelaçam, para melhor confundir, o próximo e o distante, o falecido a12 (p. 15, tradução nossa).

Benjamin (1987, p. 224) afirma nas suas teses "Sobre o conceito da história" que "os mortos não estarão em segurança se o inimigo vencer". O inimigo nesta batalha travada é o risco do esquecimento que relega ao apagamento a memória dos oprimidos, daqueles que muito pouco puderam dizer de si. Desse modo, "articular historicamente o passado não significa conhecê-lo 'como de fato foi'. Significa apropriar-se de uma reminiscência, tal como ela relampeja, no momento de um perigo" (1987, p. 224).

No texto sobre o conceito da história, o autor critica a concepção burguesa de escrever a história de uma forma cronológica e linear, na qual a historiografia estaria baseada na ideia de progresso como algo inevitável e cientificamente previsível (Gagnebin, 1987). Ele destaca o papel do "cronista" que é assumido pelo historiador comprometido com a narração das histórias pouco dignas de serem lembradas e que se sente impelido de escutar o que fora silenciado. Trata-se de um desafio de escutarmos "nas vozes que escutamos, ecos das vozes que emudeceram" (Benjamin, 1987, p. 223). Aquele que encara a história por essa perspectiva precisa dar a ver a barbárie soterrada sob os monumentos que a história tradicional foi capaz de erigir, se assim quiser acender uma centelha de esperança.

Recorrendo mais uma vez à história das palavras, de acordo com Ricœur (2007) os gregos possuíam duas expressões para designar a memória: "mnémé" e "anamnésis". O termo "Mnémé" refere-se a uma lembrança capaz de aparecer passivamente no espírito como uma afeç̧ão (um pathos), como uma imagem do passado que advém ao pensamento enquanto uma função cognitiva. Já o vocábulo "anamnésis" remete a uma lembrança que precisa ser buscado ativamente, enquanto uma pragmática. Segundo o autor, "lembrar-se é ter uma lembrança ou ir em busca de uma lembrança" (Ricœur, 2007, p. 23).

A pragmática da lembrança torna-se um imperativo da luta contra o esquecimento. Isso porque os rastros do passado, aquilo que mantém junto a "presença do ausente e ausência da presença", são por demais fugazes e estão sempre sob o risco iminente de desaparecer completamente (Gagnebin, 2009, p. 101). Não podemos esquecer que muitos arquivos dos campos de concentração foram incinerados; os fornos crematórios e as câmeras de gás de Auschwitz foram explodidos; inúmeros cadáveres, já em decomposição, foram 
exumados de suas valas rasas pelos sobreviventes, nos últimos dias da guerra, para serem queimados em grandes fogueiras para que não sobrasse nenhum rastro. Fonte??

Ainda sobre os riscos do esquecimento, Weinrich (2001) e Gagnebin (2009) mencionam a épica viagem mitológica de Ulisses no retorno a Ítaca, sua terra natal, depois de terminada a Guerra de Troia. Em sua jornada, Ulisses precisou enfrentar tempestades, naufrágios, criaturas fantásticas e terras inóspitas; contudo, o que mais lhe custou foi lutar contra as tentações do esquecimento. $O$ episódio na ilha dos Lotófagos, narrado no canto IX, é um exemplo disso. $\mathrm{Na}$ ocasião, após ancorar na costa desconhecida, o viajante enviou parte da tripulação para investigar as condições do local; porém, os espias não retornaram. Temendo pelo destino desses homens que se demoravam, o herói saiu em busca dos seus companheiros e acabou percebendo que eles foram recebidos com hospitalidade pelos habitantes do lugar. Os moradores daquela ilha haviam servido para os visitantes uma fruta agradável, doce como mel, chamada lótus, da qual eles também se alimentavam (por isso eram chamados de lotófagos). Além de saboroso, o fruto tinha o poder de fazer esquecer. Os companheiros de Ulisses foram seduzidos pelos nativos e estavam embriagados com as "delícias do esquecimento", não havendo neles mais nenhuma intenção de prosseguir viagem e voltar a ítaca. Foi necessário capturá-los e amarrá-los aos bancos da embarcação para que não desertassem durante o retorno.

Mas Ihes ofertam loto; o mel provando,

Os nossos o recado e a pátria esquecem,

Querem permanecer para o gostarem.

Constrangidos e em lágrimas os trago

E amarro aos bancos; apressado os outros

Sócios recolho, a fim que do regresso

A doçura falaz os não deslembre.

Em fila, a salsa espuma a remos ferem,

E dali pesarosos nos partimos (Homero, 2009, p. 98)

Ao analisar esse poema clássico da literatura universal, datado do século IX a.C, Gagnebin (2009, p. 15) afirma:

(...) a luta de Ulisses para voltar a Ítaca é, antes de tudo, uma luta para manter a memória e, portanto, para manter a palavra, as histórias, os cantos que ajudam os homens a se lembrarem do passado e, também, a não se esquecerem do futuro.

Primo Levi (1988, p. 88), a respeito dos horrores vividos no campo de concentração nazista, questionava se realmente vale à pena, "se 
convém que de tal situação humana reste alguma memória. A essa pergunta, tenho a convicção de poder responder que sim. Estamos convencidos que nenhuma experiência humana é vazia de conteúdo, de que todas merecem ser analisadas". Esse sobrevivente relata em sua literatura de testemunho o sonho que o assombrava durante aquelas intermináveis noites no campo. Em seus devaneios oníricos, via-se novamente em casa, depois da desastrosa passagem por Auschwitz; estando ele entre tantas pessoas conhecidas e com tanto para contar, ninguém o escutava, ninguém suportava ouvir aquela abominável narrativa, que punha todos em silêncio e absortos na condição de indiferença. O apelo à lembrança fica evidente em seu poema/súplica:

Vocês que vivem seguros

em suas cálidas casas, vocês que, voltando à noite, encontram comida quente e rostos amigos, pensem bem se isto é um homem que trabalha no meio do barro, que não conhece paz, que luta por um pedaço de pão, que morre por um sim ou por um não.

Pensem bem se isto é uma mulher, sem cabelos e sem nome, sem mais força para lembrar, vazios os olhos, frio o ventre, como um sapo no inverno.

Pensem que isto aconteceu:

eu lhes mando estas palavras.

Gravem-na em seus corações, estando em casa, andando na rua, ao deitar, ao levantar; repitam-nas a seus filhos.

Ou, senão, desmorone-se a sua casa, a doença os torne inválidos, os seus filhos virem o rosto para não vê-los. (Levi, 1988, p. 9).

A noção de testemunha que nos é oferecida por Gagnebin (2009) parece interessante, quando tratamos do trabalho com essas narrativas "insuportáveis":

[a] testemunha não seria somente aquele que viu com seus próprios olhos [...]. Testemunha também seria aquele que não vai embora, que consegue ouvir a narração insuportável do outro e que aceita que suas palavras levem adiante, como num 
revezamento, a história do outro: não por culpabilidade ou por compaixão, mas porque somente a transmissão simbólica, assumida apesar e por causa do sofrimento indizível, somente essa retomada reflexiva do passado pode nos ajudar a não repeti-lo infinitamente, mas a ousar esboçar uma outra história a inventar o presente (Gagnebin, 2009, p. 57).

O cronista, cuja função se assemelha a de uma testemunha, é aquele que é capaz "de levar em consideração os sofrimentos acumulados e de dar uma nova face às esperanças frustradas". (Gagnebin, 1987, p. 8). Ao ajudar os vivos a lembrar dos seus mortos, ele aceita o compromisso ético-político de remexer os escombros; de transitar por entre as ruínas de uma catástrofe única que inicia no passado, mas que não cessa no presente simplesmente pelo progresso do tempo, como assevera Benjamin (1987).

A essa altura é importante dizermos que essa insistência em relação ao passado precisa estar atenta para se desvencilhar de uma sacralização estéril das lembranças. Os possíveis abusos da memória tendem a ser movidos por um certo gozo ante o espetáculo do horror, sendo que as narrativas são revisitadas e reviradas em termos de uma identificação com as vítimas (ou com os algozes), ou ainda, promovendo uma fixação obsessiva ao passado na direção de um ressentimento melancólico e aprisionador. Nas palavras de Gagnebin (2009, p.55), a rememoração

... em vez de repetir aquilo de que se lembra abre-se aos brancos, aos buracos, ao esquecido e ao recalcado, para dizer com hesitações, solavancos, incompletude, aquilo que ainda não teve direito nem à lembrança nem às palavras. $A$ rememoração também significa uma atenção precisa ao presente, em particular às estranhas ressurgências do passado no presente, pois não se trata somente de não esquecer o passado, mas também de agir sobre o presente.

Lembrar, nesse caso, está relacionado com uma provocação em relação ao presente, no sentido de indagá-lo e intervir nele. "Não nos envergonhamos de manter o olhar fixo no inenarrável. Mesmo ao preço de descobrirmos que aquilo que o mal sabe de si, encontramolo facilmente também em nós" (Agamben, 2008, p. 42).

\section{A Escrita como Insurgência}

“Escreve-se sempre para dar a vida, para liberar a vida aí onde ela está aprisionada, para traçar linhas de fuga" (Deleuze, 1992, p. 176). 
$\mathrm{Na}$ "carta aos Dottores", Pierina escreve páginas e páginas contando aos médicos suas reminiscências. A camponesa, descendente de imigrantes italianos, de uma colônia de Garibaldi/RS, foi internada no Hospício São Pedro para fins de observação, pois as "perturbações mentais" que a acometiam, conforme constatações da época, levaram-na a matar por afogamento sua filha de um ano e cinco meses em uma bacia de lavar roupas no porão de casa. A carta se inicia com a seguinte frase: "Senhores Dottores. Eu escrevi esta carta para esplicar todo ho que tenho pasado neste triste mundo" a13. O texto descreve a sua vida de precariedades, a falta de dinheiro para comer e vestir. Conta sobre o árduo trabalho de dia e de noite, tanto na roça, quanto nas lidas domésticas, assim como na confecção de tapetes e chapéus artesanais com palha trançada. Pierina fala sobre a morte do pai; sobre os infortúnios do casamento; sobre o falatório da vizinhança que a tinha como louca. Ela não esconde o afogamento da filha, e diz que o fez a fim de poupá-la dos desgostos desta vida, dando-Ihe a oportunidade de gozar das felicidades do céu.

A epístola de Isauro aos médicos do Hospício São Pedro, citada anteriormente, é semelhante à carta escrita anos depois por Antonin Artaud a14. Ambos desafiam a hegemonia do saber psiquiátrico, assim como suas práticas e pedem explicações para aqueles que supostamente? detêm o poder. O jovem Isauro, que veio de Pelotas/RS para Porto Alegre para trabalhar no Telegrapho Federal, foi internado no hospício por motivos que the eram completamente desconhecidos. Ele escreve cartas aos seus familiares que estavam em Pelotas e aos conhecidos da capital pedindo que, por favor, o tirassem do hospício. Aos colegas de trabalho, que o levaram até o asilo de alienados e o deixaram lá, pede explicações do porque terem feito isso com ele, sabendo que não era louco.

O trabalho com as cartas do hospício apresenta certas peculiaridades em relação aos "arquivos da loucura". Isso porque esses documentos diferem, significativamente, dos prontuários, dos relatórios periciais, dos atestados de insanidade, das ocorrências policiais e de outras fontes que costumam ser tomadas como objeto de análise nos estudos dessa natureza. Murat (2012), partindo de sua experiência com arquivos de hospitais psiquiátricos, afirma que é muito difícil pensarmos a história da loucura desvinculada da história do alienismo e da psiquiatria, pois o discurso do louco, na maioria das vezes, nos é dado pela escrita do médico que o interpreta e o descreve. A análise dos prontuários do Hospício São Pedro nos mostra que não só o médico, mas vários outros personagens, como delegados, chefes de polícia, sacerdotes, familiares e até os vizinhos escreviam sobre os loucos, sobre as supostas razões para as suas loucuras, sobre as necessidades de internação daqueles que julgavam alienados etc. 
Instaura-se, portanto, uma tensão que coloca de um lado o discurso sobre o louco e de outro lado o discurso do louco. Essa diferenciação é extremamente relevante quando pensamos sobre as fontes de pesquisa em história da loucura e da psiquiatria, assim como nos paradigmas historiográficos que sustentam essas narrativas. $\mathrm{Na}$ medida em que as cartas foram escritas por aqueles que eram considerados loucos, podemos então dizer que os documentos que encontramos nos colocam empiricamente diante da escritura de quem o direito à palavra foi compulsoriamente aniquilado e a voz imperiosamente coagida no contexto de internação nos hospícios para "insensatos". É claro que não só as cartas, mas outros documentos podem assumir essa função de dar ouvidos às vozes que foram caladas nesse interjogo das relações de poder que se tornam assimétricas, quando se trata dos oprimidos, ou seja, quando se trata daqueles que não podem falar e que, quando o fazem, não encontram formas de serem ouvidos (Spivak, 2010).

Há uma tendência historiográfica que vem sendo desenvolvida nos últimos anos que procura dar ênfase à "história vista de baixo". Essa concepção coloca em questão o "lugar da enunciação", deslocando-o da posição consagrada do especialista (dos grupos hegemônicos) e dando visibilidade à enunciação do subalterno (dos grupos subordinados), dos que estão à margem: as mulheres, os trabalhadores, os colonizados, os doentes e, evidentemente, os loucos. No caso desses últimos, trata-se de contrastar seus escritos (cartas, diários e outros documentos, em geral anexados aos arquivos clínicos) com os documentos escritos pelos psiquiatras, que reivindicam para si um lugar de objetividade, cientificidade e da verdade sobre a loucura, dando visibilidade às narrativas das experiências da loucura do ponto de vista daquele que viveu a experiência do confinamento.

A literatura epistolar pode nos dar informações sobre o funcionamento e o cotidiano dos estabelecimentos psiquiátricos desde a perspectiva dos confinados, sobre suas preocupações, suas angústias e medos, e, em última instância, sobre a experiência da loucura desde a perspectiva do paciente a15. (Huertas, 2013, p. 7, tradução nossa).

A respeito da literatura epistolar, podemos constatar que, nos séculos XIX e XX, era recorrente a prática de se manterem guardadas nos prontuários as cartas escritas por pacientes internados em hospícios, tal como ocorreu com as correspondências que encontramos nos arquivos do São Pedro. As pesquisas já citadas de Beveridge (1997), Lavín (2003), Ríos (2004) e Villasante et al. (2016) mostram que isso ocorreu em manicômios de diferentes países (Escócia, Chile, México e Espanha, respectivamente). Ao analisarmos os trabalhos desses 
autores notamos que eles compartilham dessa abordagem historiográfica que dá ênfase à "história vista de baixo". Beveridge (1997) afirma que um dos objetivos daquele seu trabalho é "permitir que a voz do paciente do século XIX seja ouvida" al6 (p. 900, tradução nossa).

Lavín (2003), por sua vez, diz que:

... a principal razão que mobiliza a sua publicação [das cartas] é a ilusão de liberar do confinamento todas essas vozes que nunca chegaram ao seu destino. Todos os autores pedem algo aos seus destinatários: querem ser visitados, que tragam suas coisas, que os acolham ou que os livrem do diagnóstico que os obriga ao exílio. $O$ fato de as cartas não terem sido enviadas por quaisquer que sejam as razões desse descuido - frustra o intento de eles serem escutados e encontrarem-se com os outros, impulso comum a todos nós a17. (p. 7, tradução nossa).

Nessa mesma perspectiva, Ríos (2004, p. 20, tradução nossa) afirma:

Seguindo a tendência historiográfica que expõe a necessidade de abordar o ponto de vista do subalterno, este escrito pretende resgatar a voz daqueles loucos que quiseram que suas palavras fossem escutadas pelas autoridades médicas, políticas, judiciais ou mesmo pela família, mas foram desprezadas ao serem tomadas como consequências próprias da loucura a18.

Villasante et al. (2016, p. 121, tradução nossa), do mesmo modo, anunciam a sua intenção de analisar, nas cartas que encontraram, a "experiência subjetiva da internação, 'o ponto de vista' do paciente. Pretendemos assim contribuir para pensar a loucura - e a história da loucura - de outra maneira, 'desde baixo', dando voz aos 'sem voz'" a19.

As cartas do hospício suscitam uma certa perplexidade pela subversão que provocam ao silenciamento a qual estavam submetidos os loucos. Elas afrontam o projeto de esquecimento, instigando o movimento das engrenagens das relações de poder, incitando uma agonística, produzindo fissuras nos muros do hospício e rompendo com essa condição de silenciamento aterradora.

Tais escritos potencialmente insurgentes foram capturados e impedidos de alcançar os destinos previstos pelos seus autores, ao passo que foram lançados nos prontuários, fazendo o silêncio ganhar contornos palpáveis, levando-nos a um insólito encontro com a superfície do esquecimento. No entanto, o contato com esses 
documentos, que não se resignam a uma posição sepulcral, permitenos encontrar com os efeitos de resistência daqueles que puderam testemunhar algo de suas vidas e do seu tempo, cabendo, portanto, ao trabalho com as cartas do hospício permitir que essas vozes sejam escutadas.

\section{Referências}

Agamben, G. (2008). O que resta de Auschwitz: o arquivo e a testemunha. São Paulo: Boitempo.

Benjamin, W. (1987). Sobre o conceito da História. In W. Benjamin, Magia e técnica, arte e política: ensaio sobre literatura e história da cultura (Obras escolhidas, Vol. 1). São Paulo: Brasiliense.

Beveridge, A. (1997). Voices of the mad: patients' letters from the Royal Edinburgh Asylum, 1873-1908. Psychological Medicine, 27, 899-908. doi: 10.1017/S003329179700490X

Costa, J. F. (1989). História da psiquiatria no Brasil: um corte ideológico. Rio de Janeiro: Xenon.

Cunha, M. C. P. (1986). O espelho do mundo: Juquery, a história de um asilo. Rio de Janeiro: Paz e Terra.

Deleuze, G. (1992). Conversações. São Paulo: Ed. 34.

Engel, M. G. (2001). Os delírios da razão: médicos, loucos e hospícios (Rio de Janeiro, 1830-1930). Rio de Janeiro: Editora Fiocruz.

Facchinetti, C., Ribeiro, A., Chagas, D. C., \& Reis, C. S. (2010). No labirinto das fontes do Hospício Nacional de Alienados. História, Ciências, Saúde-Manguinhos, 17(Suppl. 2), 733-768. doi: 10.1590/S0104-59702010000600031

Farge, A. (1989). Le goût de l'archive. Paris: Éditions du Seuil.

Foucault, M. (2011a). Vigiar e punir: nascimento da prisão. Petrópolis: Vozes.

Foucault, M. (2011b). A ordem do discurso: aula inaugural no Collège de France, pronunciada em 2 de dezembro de 1970. São Paulo: Edições Loyola.

Foucault, M. (2007). História da loucura: na idade clássica. São Paulo: Perspectiva.

Foucault, M. (2006a). A vida dos homens infames. In M. Foucault, Estratégia, poder-saber (Ditos e escritos, Vol. 4). Rio de J aneiro: Forense Universitária.

Foucault, M. (2006b). O poder psiquiátrico: curso dado no Collège de France (1973-1974). São Paulo: Martins Fontes.

Foucault, M. (2006c). A ética do cuidado de si como prática da liberdade. In M. Foucault, Estratégia, poder-saber (Ditos e escritos, Vol. 4). Rio de Janeiro: Forense Universitária. 
Foucault, M. (2004). A escrita de si. In M. Foucault, Ética, sexualidade, política (Ditos e escritos, Vol. 5). Rio de Janeiro: Forense Universitária.

Foucault, M. (1979). Microfísica do Poder. Rio de Janeiro: Edições Graal.

Gagnebin, J. M. (2009). Lembrar escrever esquecer. São Paulo: Ed. 34.

Gagnebin, J. M. (1987). Prefácio - Walter Benjamin ou a história aberta. In W. Benjamin, Magia e técnica, arte e política: ensaio sobre literatura e história da cultura. (Obras escolhidas, Vol. 1). São Paulo: Editora Brasiliense.

Galvão, W. N. (2008). A margem da carta. Teresa: revista de literatura brasileira, 34(8/9), 14-29.

Homero. (2009). Odisséia. São Paulo: Atena Editora.

Huertas, R. (2013). Another history for another psychiatry. The patient's view. Culture \& History Digital Journal, 2(1), 1-11. doi: 10.3989/chdj.2013.021

Lavín, A. (2003). Cartas desde la Casa de Orates. Santiago de Chile: Ediciones de la Dirección de Bibliotecas, Archivos y Museos, Centro de Investigaciones Diego Barros Arana.

Levi, P. (1988). É isto um homem?. Rio de Janeiro: Rocco.

Lima, A. de A., \& Holanda, A. F. (2010). História da psiquiatria no Brasil: uma revisão da produção historiográfica (2004-2009). Estudos e Pesquisas em Psicologia, 10(2), 572-595. Recuperado de http://pepsic. bvsalud.org/scielo.php?script=sci_arttext\&pid=S1 808-42812010000200017

Lobo, L. F. (2008). Os infames da história: pobres, escravos e deficientes no Brasil. Rio de J aneiro: Lamparina.

Machado, R., Lureiro, A., Luz, R., \& Muricy, K. (1978). Danação da norma: a medicina social e constituição da psiquiatria no Brasil. Rio de Janeiro: Edições Graal.

Murat, L. (2012). O homem que se achava Napoleão: por uma história política da loucura. São Paulo: Três Estrelas.

Ricœuer, P. (2007). A memória, a história, o esquecimento. Campinas: Editora da Unicamp.

Ríos, A. (2004). Locos letrados frente a la psiquiatría mexicana a inicios delsiglo XX. Frenia, 4(2), 17-35. Recuperado de http: //www.revistaaen.es/index. php/frenia/article/view/16408/ 16254

Santos, N. M. W. (2008). Narrativas da loucura e história de sensibilidades. Porto Alegre: Editora da UFRGS.

Silva, R. N., Hartmann, S., Scisleski, A. C. C., \& Pires, M. L. (2008). As patologias nos modos de ser criança e adolescente análise das internações no Hospital Psiquiátrico São Pedro entre 1884 e 1937. Revista Psico, 39(4), 448-455. 
Scotti, Z. R. (2011). Imigrantes alemãs: por uma contextualização para internamento no Hospício São Pedro. Historiae: revista de história da Universidade Federal de Rio Grande, 2(3), 243-256.

Scotti, Z. R. (2013). Que loucura é essa? loucas e loucos italianos no Hospício São Pedro em Porto Alegre/RS (1900-1925) (Tese de Doutorado). Pontifícia Universidade Católica do Rio Grande do Sul - PUCRS, Porto Alegre, RS, Brasil.

Spivak, G. C. (2010). Pode o subalterno falar? Belo Horizonte: Editora da UFMG.

Trevizani, T. M., \& Silva, R. N. (2014). Camisa de força para menores: patologias de crianças e adolescentes (Hospício São Pedro, 1884-1929). Mnemosine, 10, 142-166.

Venancio, A. T. A., \& Cassilia, J. A. P. (2010). A doença mental como tema: uma análise dos estudos no Brasil. Espaço Plural, 9(22), 24-34.

Villasante, O., Vázquez de la Torre, P., Conseglieri, A., \& Huertas, R. (2016). Letras retenidas: experiencias de internamiento en las cartas de los pacientes del Manicomio de Santa Isabel de Leganés, Madrid (1900-1950). Culturas Psi, (6), 118-137. Recuperado de http://ppct.caicyt.gov.ar/index.php/culturaspsi/article/viewFile/ 8328/pdf_1

Wadi, Y. M. (2003). A história de Pierina e as interpretações sobre processos de sofrimento, perturbação e loucura (RS/Brasil, século XX). Horizontes, Bragança Paulista, 21, 83-103.

Wadi, Y. M. (2011). "Entre muros": os loucos contam o hospício. Topoi (Rio de Janeiro), 22(12), 250-269. doi:10.1590/2237$101 X 012022014$

Wadi, Y. M. (2014). Olhares sobre a loucura e a psiquiatria: um balanço da produção na área de História (Brasil, 1980-2011). História Unisinos, 18(1), 114-135. doi: 10.4013/htu.2014.181.11

Wadi, Y. M. (2002). Palácio para guardar doidos: uma história das lutas pela construção do hospital de alienados e da psiquiatria no Rio Grande do Sul. Porto Alegre: Editora da Universidade/UFRGS.

Weinrich, H. (2001). Lete: arte e crítica do esquecimento. Rio de Janeiro: Civilização Brasileira.

\section{Endereço para correspondência \\ Tiago Marcelo Trevizani}

Universidade Federal do Rio Grande do Sul - UFRGS

Instituto de Psicologia

Rua Ramiro Barcelos, 2600, CEP 90035-003, Porto Alegre - RS, Brasil

Endereço eletrônico: tiagotrevizani@hotmail.com 


\section{Rosane Azevedo Neves da Silva}

Universidade Federal do Rio Grande do Sul - UFRGS

Instituto de Psicologia

Rua Ramiro Barcelos, 2600, CEP 90035-003, Porto Alegre - RS, Brasil

Endereço eletrônico: rosane.neves@ufrgs.br

Recebido em: 03/03/2019

Reformulado em: 23/04/2019

Aceito em: 25/04/2019

\section{Notas}

* Psicólogo. Doutorando do Programa de Pós-Graduação em Psicologia Social e Institucional da Universidade Federal do Rio Grande do Sul (PPGPSI - UFRGS). Atua no Núcleo de Apoio Pedagógico (NAP) da Secretaria Municipal de Educação de Novo Hamburgo/RS (SMED/NH).

** Psicóloga. Doutora em Educação pela UFRGS. Professora Titular do Instituto de Psicologia da Universidade Federal do Rio Grande do Sul. Participa da Linha de Pesquisa "Clínica, Subjetividade e Política" do Programa de Pós-Graduação em Psicologia Social e Institucional (PPGPSI - UFRGS).

${ }^{1}$ O Hospital Psiquiátrico São Pedro foi fundado em Porto Alegre em 1884. Até a década de 1920, era chamado Hospício São Pedro. Optamos, neste artigo, por manter este último nome, pelo fato de os documentos serem datados da época em que o estabelecimento era assim denominado.

${ }^{2}$ Os prontuários de pacientes que se internaram (foram internados?) no Hospício São Pedro entre os anos 1884 e 1973 estão sob custódia do Arquivo Público do Estado do Rio Grande do Sul (APERS), enquanto os mais recentes encontram-se no arquivo da própria instituição. O fundo APERS contabiliza 67.943 prontuários, acondicionados em mais de quatro mil caixas. O acervo é de consulta restrita, tendo em vista que se trata de documentos sigilosos. O projeto de pesquisa que deu origem a este trabalho passou pela apreciação dos Comitês de Ética da Universidade de origem e do Hospital Psiquiátrico São Pedro, recebendo parecer favorável de ambos.

3 Os nomes dos remetentes e destinatários das cartas foram substituídos por pseudônimos para preservar a identidade dos sujeitos da pesquisa. Mantivemos apenas os nomes dos destinatários que eram figuras públicas ou personalidades históricas. É importante destacar que, em relação ao pseudônimo de "Pierina", escolhemos usar o mesmo que aparece em um estudo desenvolvido por Wadi (2003). A autora também trabalha com documentos dessa paciente.

${ }^{4}$ Província de São Pedro do Rio Grande do Sul era o nome do atual Estado do Rio Grande do Sul antes da Proclamação da República em 1889.

5 Trecho da carta de Isauro ao Amigo Hipólito. Nas citações diretas, fizemos a transcrição literal dos documentos, mantendo a forma de escrita dos autores.

6 “...J'aperçutendu d'unévénementinatendu. En elle, tout se focalise sur quelques instants de vie de personnages ordinaires, rarement visités par l'histoire". (Farge, 1989 , p. 13)

${ }^{7}$ Carta de Isauro ao Dr. Dioclécio Pereira, diretor do Hospício São Pedro, e aos demais médicos.

8 "Patients wrote for a great variety of reasons: to describe their torments, to make sense of their distress, to complain or to plead their sanity". (Beveridge, 1997, p. 900).

9 “... sobrevivieron a un incendio que destruyó gran parte de la antigua biblioteca del Instituto Psiquiátrico. Alguien las tomó y las guardó amorosamente en esta "caja-libro" que encontré mucho tiempo después". (Lavín, 2003, p. 7). 
10 "Pretendo demostrar la forma en que una minoría de internos letrados articularon en un discurso coherente el rechazo al concepto psiquiátrico de locura, a las prácticas terapéuticas y las relaciones sociales que regulaban la vida cotidiana del manicomio". (Ríos, 2004, p. 21).

11 “... nunca fueron tramitadas [las cartas] por los responsables del establecimiento, que las adjuntaron a la historia clínica del escribiente como documento anejo capaz de ilustrar o confirmar la patología del sujeto, o como información adicional con la que valorar sus "resistencias" al internamiento. (Villasante et al., 2016, p. 123).

12 “... accomplir un miracle, celui de rattacher le passéau présent ; en la découvrant, on se prend à penserqu'onnetravaille plus avec les morts (I'histoire est certainement d'abord une rencontré avec le mort), et que la matiè reest si aiguë que elle sollicite simultanément l'affectivité et l'intelligence. Sentimentrare que cette soudainerencontreavec des existences inconnues, accidentées et remplies, qui mêlent, comme pourmieuxembrouiller, le proche (si proche) et le lointain, le défunt". (Farge, 1989, p. 15).

${ }^{13}$ Carta de Pierina aos Senhores “Dottores”, escrita entre 1909 e 1911.

${ }^{14}$ Carta de Antonin Artaud aos Médicos-chefe dos manicômios (1925). Disponível em: http://redehumanizasus.net/89562-antonin-artaud-carta-aos-medicos-chefesdos-manicomios-1925/

${ }^{15}$ This epistolary literature can give us information on the functioning and everyday life of psychiatric establishments from the perspective of the confined, on their worries, their anguishes and fears, and, ultimately, on the experience of ill $\neg$ ness from the perspective of the patient. (Huertas, 2013, p. 7).

16 "... to allow the voice of the nineteenth century patient to be heard." (Beveridge, 1997, p. 900).

${ }^{17}$ La principal razón que moviliza su publicación es la ilusión de liberar del encierro estas voces que nunca llegaron a su destino. Todos sus autores, sin excepción, piden algo a los destinatarios de sus cartas: quieren ser visitados, que les traigan sus cosas, que los abriguen o que los liberen de ese diagnóstico que los condena al exilio. El hecho de que estas cartas no hayan sido enviadas - cualquiera fuesen las razones de este descuido - no hacía más que frustrar su intento por ser escuchados y encontrarse con el otro, impulso común a todos nosotros. (Lavín, 2003, p. 7).

${ }^{18}$ Siguiendo la tendencia historiográfica que plantea la perentoriedad de abordar el punto de vista del subalterno, este escrito pretende rescatar la voz de aquellos locos que quisieron que sus palabras fuesen escuchadas por las autoridades médicas, políticas, judiciales o por la misma familia, pero que fueron desdeñadas al ser toma das como consecuencias propias de la locura. (Ríos, 2004, p. 20).

19 “... la experiencia subjetiva del internamiento, el 'punto de vista' del paciente. Pretendemos así contribuir a pensar la locura -y la historia de la locura- de otra manera, "desde abajo", dando voz a los 'sin voz'”. (Villasante et al., 2016, p. 121).

Este artigo de revista Estudos e Pesquisas em Psicologia é licenciado sob uma Licença Creative Commons Atribuição-Não Comercial 3.0 Não Adaptada. 